\title{
Analysis The Effect Of Internal Geometry On The Mechanical Properties Of Acrylonitril Butadiene Styrene (ABS) Materials Prepared Using 3D Printing
}

\author{
Ivan Junaidy Abdul Karim, Sukiman B, and Muhammad Fadly Hi. Abbas \\ Department of Mechanical Engineering, Faculty of Engineering, Khairun University, Indonesia
}

\begin{abstract}
The process of research and refinement of Fused Deposition Modeling 3D Printer, surely contains many variables and parameters with the aim of generating a 3D object with the results and the level of accuracy approaching its original design and can be applied as the expected design. In addition to the effect of printer type on the FDM method, the filament material used as a filler to print 3D objects certainly has different mechanical and physical characteristics, thus allowing for different object results for each different filament material. This research was conducted to determine the effect of internal variations of its geometry and dimensions on the mechanical properties of ABS using a 3D Printer. The internal geometries that are varied are triangle and honeycomb, with variations in thickness for each geometry are $1 \mathrm{~mm}$ and 2 $\mathrm{mm}$, and variations in the axis of symmetry are $4.5 \mathrm{~mm}$ and $9 \mathrm{~mm}$. The results showed that the control sample had tensile and bending strength results that matched the ABS filament datasheet reference. Objects with an internal geometry triangle in the size $4.5 \mathrm{~mm}$ and $2 \mathrm{~mm}$ of thickness have better tensile and bending strength than honeycomb geometry.
\end{abstract}

Keywords: 3D Printing; internal geometry; Acrylonitrile butadiene styrene; mechanical properties

\section{Introduction}

Three-dimensional (3D) printing is one of the most reliable and revolutionary machines in additive manufacturing (AM) techniques to create threedimensional objects with unique and diverse structures. Up to now, these techniques include fused deposition modeling (FDM), stereolithography apparatus (SLA), continuous liquid interface production (CLIP), digital light processing, and selective laser sintering (SLS). In the late 1980s, S. Scott Crump developed the FDM 3D printer and it was commercialized in 1990 by Stratasys. Now, FDM has become the most widely applied 3D printing method because of its convenience, low operating costs, and environmental friendliness.

A research has been conducted in 2016 on the design of the internal effect of geometry on the resulting mechanical properties.[13] This research compares the sample with stipes, circle, and honeycomb geometries. There are still shortcomings from this research, namely the use of the type of printer and the orientation direction that so many internal geometry variables that will be observed are affected by the printing orientation.

Two years earlier, a German researcher named Enno Ebel had previously conducted research on the effect of internal geometry variations on the mechanical properties of 3D Printer printed samples. The printers used in his research are commercial printers that are commonly sold in the market. However, there are still shortcomings from that research, one of it is the size and thickness of the object cannot be varied.

Departing from these conditions, more specific research on the influence of internal geometry on the mechanical properties of the materials used in 3D Printer machines needs to be carried out. In addition, the selection of the type of commercial printer is also an option in order to know the performance and application opportunities on a large scale.

This study will analyze the mechanical properties of 3D printed FDM objects which are influenced by the type of filament material, the internal geometry design, and the ratio of its dimensions. The research data is expected to be used as a reference or consideration in making threedimensional objects using FDM 3D printing.

Rapid Prototyping (RP) can be defined as the methods used to make scale models (prototypes) from the start of a product (part) or product assembly quickly using 3D computer aided design (CAD) data.[11] The first RP method was discovered in 1986 in California, USA, namely the Stereolithography method. After the discovery of this method, various other methods have been developed that allow rapid prototyping. The Rapid Prototyping process begins with the validation of the 
product's 3D CAD model.[3] The valid model is then oriented to the manufacturing space (part orientation). The concept of rapid prototyping is to divide objects with a small thickness according to the cross-section of the object. Furthermore, the rapid prototyping machine makes 3D products by adding materials layer by layer according to the division of the cross-section of the object. The quality of the surface of the object depends on the layer thickness of the rapid prototyping machine. The smaller the layer thickness, the better the surface quality. Fused Deposition Modeling is a method of making a prototype by melting thermoplastic material using an extruder mechanism. Then the prototyping process goes through a layer-by-layer process.[10] Research on the development of Rapid Prototyping technology for the manufacture of multi-material products has been conducted.[11] The results of this research stated that by using the hopper work nozzle mechanism as a powder deposition device for product and slot feeder counter rolling cylinder for supporting powder various characteristics of multimaterial products can be made. It is known as a whole that it can be seen that rapid prototyping technology has had a very significant influence in the medical field, and with further research and development these technologies will continue to contribute to rapid, inexpensive and effective development.[14] Until now, studies on the use of rapid prototyping are still being carried out to produce products of good quality, and in the shape that match their original dimensions.[8]

\section{Method}

\subsection{Fused Deposition Modelling 3D Printing}

The Fused Deposition Modeling 3D Printing method is a rapid prototyping technology developed by Stratasys using thermoplastic materials. The development of this technology continued, until a 3D design company managed to find a new nanocomposite material consisting of various plastic and iron materials that can be experienced until now. Currently, 3D printing technology is able to process various kinds of materials, from liquid to solid materials (liquid materials will be compacted first), and these materials already contain color, allowing creators or users to innovate directly according to their creativity on the final product. In terms of price, since the beginning of the $21^{\text {st }}$ century where technology has developed greatly, the market price for this $3 \mathrm{D}$ printer has increased. It was noted by a consultant, that in 2012 this price increased by $29 \%$ from 2011 which was 2.2 million dollars. Even so, it can be predicted that one day this technology will become public consumption that can be easily found in the market, because basically this technology can reduce the costs incurred by people to buy certain household goods, because when they have this printer they can directly create various goods according to their desire and necessity.

Generally, the working principle of a 3D printer is not that different from a common printer. The object design that will be created must first be converted into several file formats that are relevant to the application used. The initial design of the object uses a CAD application with a .dwg picture format or is done directly in the Inventor application or SolidWork or other relevant modeling application. The design results are then stored in format .stl to make layers that forms the object using 3D printing software Cura.[7]

There are various types of $3 \mathrm{D}$ printers that have been sold in the market. One of them is the RepRap brand. Different types of 3D printer machine would produce different results and their settings will also be different.

In the utilization, the $3 \mathrm{D}$ printer machine uses input material in the form of a thermoplastic polymer filament. There are two types of filament materials that are most commonly used, namely polylactic acid (PLA) and acrylonitrile butadiene styrine (ABS) which are extruded from the nozzle head, with a layer-by-layer fabrication process. The filament is softened in a liquifier above its melting temperature and pressed through a nozzle die. When the liquifier moves, the extruded polymer will descend on the bed placed in the printing machine then the $3 \mathrm{D}$ printer cartridge will move following the pattern of the design to be printed.[9]

Though it looks easy, there is a control model to set all the parameters at the same time. These parameters include: filament feeding rate, extrusion width, linear speed, and layer thickness. Those parameters are entities that affect the outcome of the FDM process.These parameters are set using the Cura 3D object printing software. There are various options panels to set the printing speed, the thickness or number of layers of the object to be printed. In addition to determining the amount of parameters of printing $3 \mathrm{D}$ objects, Cura software also serves as a slicer to determine the number of layers of .stl format object to be printed.

Although futuristic, the principle of layer-by-layer can lead to failure in $3 \mathrm{D}$ printed objects. Some parts of the 3D printed objects have lower elastic properties compared to objects made by injection molding with the same type of thermoplastic polymer. Several researchers have conducted research on the mechanical properties of 3D printed objects. One of the main focuses is to obtain a comparison of the results of the mechanical properties of objects printed using the conventional FDM method with 3D printer machines on the market.[15]

\subsection{Design of the Specimen}

The design of the specimens is presented in tables 1 to 3 . The variables used for tensile testing and bending testing refer to the ASTM standard with the number of samples for each variable is three.

Table 1. The length ratio of the specimen's internal geometry

\begin{tabular}{|c|c|c|}
\hline Filament & \multicolumn{2}{|c|}{ ABS } \\
\hline \multicolumn{3}{|c|}{ Internal Geometry } \\
\hline Control & Triangle & Honeycomb \\
\hline \multicolumn{3}{|c|}{ Geometry Internal Length Ratio } \\
\hline \multirow{2}{*}{ Solid } & $4.5 \mathrm{~mm}$ & $4.5 \mathrm{~mm}$ \\
\cline { 2 - 3 } & $9.0 \mathrm{~mm}$ & $9.0 \mathrm{~mm}$ \\
\hline
\end{tabular}


Table 2. Tensile test specimen codes

\begin{tabular}{|c|c|c|c|c|}
\hline \multicolumn{5}{|c|}{ Tensile Test } \\
\hline \multicolumn{5}{|c|}{ Internal Geometry Length Ratio of Specimen } \\
\hline $4.5 \mathrm{~mm}$ & \multicolumn{3}{|c|}{$9.0 \mathrm{~mm}$} & \multicolumn{2}{l|}{ solid } \\
\hline Honeycomb & Triangle & Honeycomb & Triangle & Control \\
\hline OB/9/H & Test Code \\
\hline
\end{tabular}

Fig 1. Design of internal geometry and dimensions (mm) of the tensile test specimen.

\section{Results and Discussion}

\subsection{Tensile test analysis}

The tensile test samples were shaped according to the ASTM D638 type I standard with a nominal thickness of each sample of $4 \pm 0.4 \mathrm{~mm}$ and a speed of testing of 5 $\mathrm{mm} / \mathrm{min}$. Tensile test was conducted in the engineering materials laboratory Universitas Gadjah Mada using Servopulser machines with a load capacity of 2 tons.

Tensile testing is carried out with the aim of knowing the mechanical properties of the polymer material to tension where the mechanical properties include the maximum tensile point, breaking point, and the character of polylactic acid. The test data obtained are in the form of nominal load when it reaches the ultimate tensile stress and maximum strain when the sample breaks. The value of the maximum tensile strength (ultimate tensile stress), is the maximum load $(\mathrm{P})$ divided by the initial crosssectional area (Ao) of the test object. [5] Figure 1 is a sample photo of the tensile test printed using a 3D Printer.

$$
\sigma=\frac{\mathrm{P}}{\mathrm{A}_{0}}
$$

Cross-sectional area (cross section area) of each sample is calculated from the cross-sectional area of the sample control area reduced by the internal geometry of each sample variable. The cross-sectional area of the $\mathrm{RAW} / \mathrm{K}$ sample is $283,385 \mathrm{~mm}^{2}$. Obtained from the multiplication of the thickness $(\mathrm{t}=4 \mathrm{~mm})$ of the sample and the width $(1=13 \mathrm{~mm})$ of the sample. While the crosssectional area for samples $\Delta \mathrm{K} / 4.5 / \mathrm{T} 15.896 \mathrm{~mm}^{2}, \Delta \mathrm{B} / 9 / \mathrm{H}$ $63.585 \mathrm{~mm}^{2}, \mathrm{OK} / 4.5 / \mathrm{T} 15.896 \mathrm{~mm}^{2}$, and $\mathrm{OB} / 9 / \mathrm{H} 63.585$ $\mathrm{mm}^{2}$. The nominal is the minimum value of the cross section area as a divider of the breaking force generated when the sample breaks.[13]

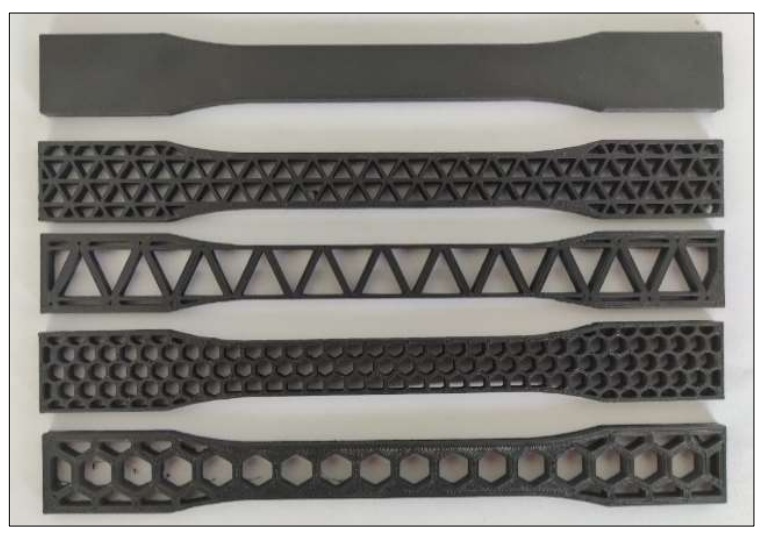

Fig 2. Tensile test sample

The strain value of each sample was obtained from the division of the measuring length extension $(\Delta \mathrm{L})$ of the specimen with the initial length (Lo).[6] The gage length value used is $57 \mathrm{~mm}$.

$$
\varepsilon=\frac{\Delta \mathrm{L}}{\Delta 0}
$$

$\mathrm{RAW} / \mathrm{K}$ or control samples are made with the aim of knowing the quality of printed samples using a 3D Printer machine, as well as being a control variable for comparison of samples with internal geometry variations.[9] The test results data for the control sample are presented in table 3 .

Table 3. Ultimate tensile strength ABS

\begin{tabular}{|c|c|c|}
\hline Sample & $\begin{array}{c}\text { BotFeeder ABS } \\
\text { Filament }\end{array}$ & RAW/K \\
\hline Tensile Strength & $5-70$ & 10.350 \\
\hline
\end{tabular}

The ultimate tensile strength data values in the table above are in accordance with ASTM D638 with the same test parameters. Reference samples obtained from the ABS filament reference datasheet ranged from 37-110 $\mathrm{MPa}$. While the maximum tensile strength of the sample prepared using a 3D Printer is $10.350 \mathrm{MPa}$. The maximum tensile strength value of the tensile test can be higher or lower, depending on the printing parameters using the 3D Printer machine. These results indicate that the selection of printing parameters using the $3 \mathrm{D}$ Printer machine is appropriate.[9]

The test results are then compared based on the type and size of each internal geometry. Figure 3 shows the tensile test results for the internal geometry of triangle.

The graph in Figure 4 presents the maximum stress and strain values when the sample with an internal triangle geometry breaks. The maximum tensile strength values of the $\mathrm{RAW} / \mathrm{K}, \Delta \mathrm{K} / 4.5 / \mathrm{T}$, and $\Delta \mathrm{B} / 9 / \mathrm{T}$ samples were 10.350 $\mathrm{MPa}, 17.064 \mathrm{MPa}$, and $15.775 \mathrm{MPa}$. While the maximum strain generated when the sample broke straight - 
respectively are $2.012 \%, 0.640 \%$ and $1.067 \%$. Based on these results, the largest ultimate tensile strength value for the internal geometry of the triangle is $17,064 \mathrm{MPa}$ belonging to the sample $\Delta \mathrm{K} / 4.5 / \mathrm{T}$. Next are the test results for the internal geometry of honeycomb.

The maximum stress and strain graphs are presented in Figure 3. Using the same control variables, the maximum stress values when a sample with honeycomb internal geometry breaks are $19.358 \mathrm{MPa}$ and $22.552 \mathrm{MPa}$ for $\mathrm{OK} / 4.5 / \mathrm{H}$ and $\mathrm{OB} / 9 / \mathrm{H}$. While the value of maximum strain resulting from both variables are respectively 1.870 $\%$ and $2.085 \%$.

The largest tensile strength value for honeycomb internal geometry is $22.552 \mathrm{MPa}$ for sample $\mathrm{OB} / 9 / \mathrm{H}$.

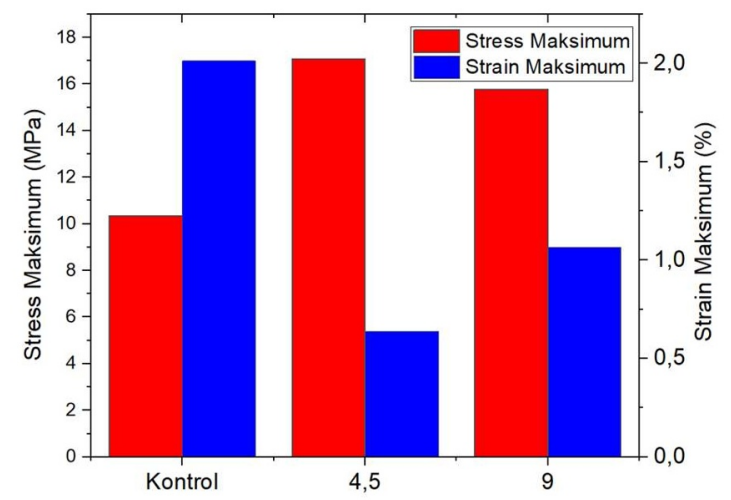

Fig 3. Graph of maximum stress-strain tensile test of the triangle sample.

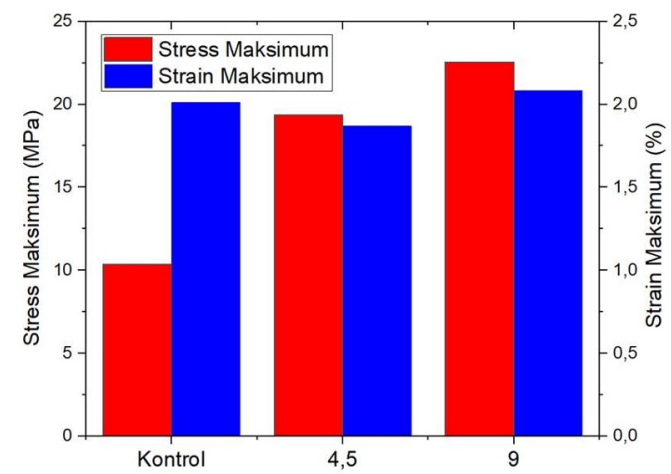

Fig 4. Graph of maximum stress-strain tensile test of the honeycomb sample.

The data in Figure 5 is a comparison of the triangle and honeycomb samples' tensile test with a symmetry axis of $4.5 \mathrm{~mm}$. The red lines represent the maximum stress value generated from each samples. It is known that the sample with internal geometry of triangle has a stress value of $17.064 \mathrm{MPa}$. This nominal is higher than the tensile test of honeycomb internal geometry sample which has maximum stress value of $19.358 \mathrm{MPa}$.

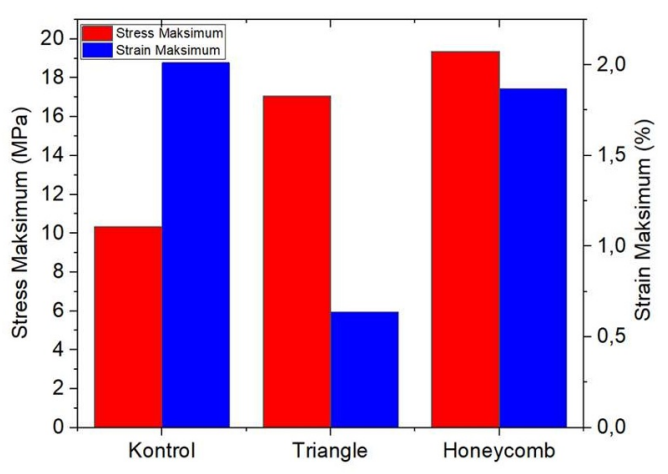

Fig 5. Graph of maximum stress-strain of the sample tensile test with an internal geometry of $4.5 \mathrm{~mm}$.

The strain values of the two samples are presented by the blue graph. Samples $\Delta K / 4.5 / \mathrm{T}$ and $\mathrm{OK} / 4.5 / \mathrm{H}$ have strain values of $0.638 \%$ and $1.870 \%$, respectively. From these data, it is known that the sample with internal geometry of triangle measuring $4.5 \mathrm{~mm}$ in symmetry axis can withstand greater stresses than the sample with honeycomb internal geometry on the symmetry axis size.

The UTS generated by the $\Delta K / 4.5 / T$ sample has the lowest value compared to RAW/K and $\mathrm{OK} / 4.5 / \mathrm{H}$ because the $\Delta \mathrm{K} / 4.5 / \mathrm{T}$ sample is the sample with a geometry that has most voids.

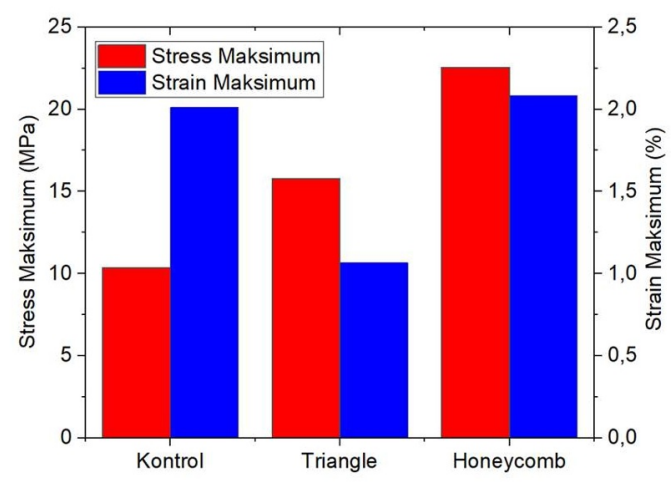

Fig 6. Graph of maximum stress-strain of the sample tensile test with an internal geometry of $9 \mathrm{~mm}$.

Next is a comparison between samples with a $9 \mathrm{~mm}$ axis of symmetry for samples with internal geometries of triangle and honeycomb shown in Figure 6.

Both internal geometries are capable of producing higher maximum stress values than RAW/K samples. The maximum stress and strain values of the triangle sample are $15.775 \mathrm{MPa}$ and $1,067 \%$. Then the sample with honeycomb internal geometry has a value of $22.552 \mathrm{MPa}$ and $2.085 \%$ which is the maximum stress and strain value of the sample. The analysis of graphs presented in Figure 2 and 3 shown that from each size of the axis of symmetry $4.5 \mathrm{~mm}$ and $9 \mathrm{~mm}$, the samples with the internal geometry of the triangle shows the maximum value of the stress and strain that is better than the sample RAW/K and samples with honeycomb internal geometry.

Differences in the strength valuation of each size and geometry shape is certainly influenced by the selection of size variation and geometry shape, as well as the influence of the print process using a $3 \mathrm{D}$ printer. 
Layer thickness on the printing process affects the mechanical performance of the test sample.[9] An explanation of the effect of layer thickness on the performance of the print sample will be explained in the next section.

The strain values of each variation of the internal geometry size with the highest tensile strength $(\Delta \mathrm{B} / 9 / \mathrm{T}$ and $\mathrm{OB} / 9 / \mathrm{H}$ ) are $1.067 \%$ and $2.085 \%$. This nominal is lower than the strain of RAW/K which is $2.012 \%$.

Overall, the maximum strain value is in the range of $0.5-2.1 \%$. It is greater than the range of strain values from the reference data which ranges from $1-6 \%$. This happens because during the printing process, the printer bed is set at the ABS glass transition temperature of $60^{\circ} \mathrm{C}$. At the glass temperature, thermoplastic polymers change their state and behaviour from rigid, brittle, solid like glass to flexible, soft, elastic like fluids (visco-elastic).

The percent strain resulted from all samples has a range that is not too big because the characteristics of the basic material used are the same. The difference that makes the value smaller than the percent strain of the $\mathrm{RAW} / \mathrm{K}$ sample is the influence of the internal geometry that is able to withstand certain loads that are different from the RAW/K sample.[4]

More specifically to the properties that can be known and the analysis of the internal effect of geometry on its mechanical properties, the values of stress $(\sigma)$ and strain $(\varepsilon)$ are converted in the form of a graph of the modulus of elasticity (E). The modulus of elasticity is a measure of the stiffness of a material. The greater the modulus, the smaller the elastic strain produced due to the application of stress. Since the modulus of elasticity is required for the calculation of the bending of the member, the elastic modulus is an important design value.[5]

$$
\mathrm{E}=\frac{\sigma}{\varepsilon}
$$

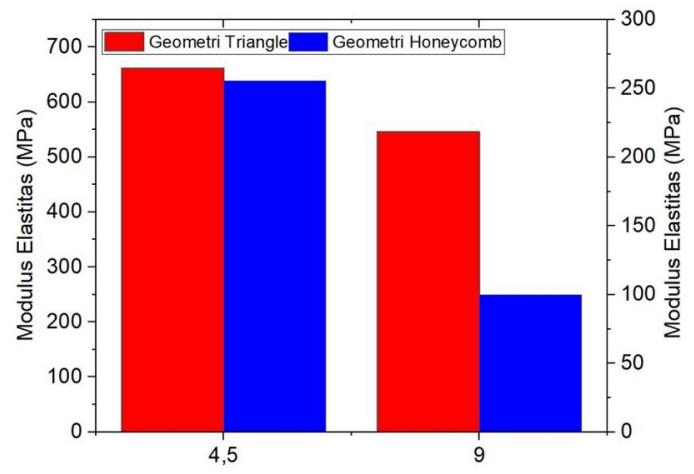

Fig 7. Tensile test modulus graph

The modulus of elasticity graph in Figure 7 shows the overall sample data with internal variations in the geometry of the test results. The elastic modulus values for samples with an internal geometry of triangle are $661.674 \mathrm{MPa}$ and $545.895 \mathrm{MPa}$ for $4.5 \mathrm{~mm}$ and $9 \mathrm{~mm}$ sizes. While the modulus of elasticity of $255.483 \mathrm{MPa}$ and 100.126 MPa are owned by samples with honeycomb internal geometry with axes of symmetry $4.5 \mathrm{~mm}$ and 9 $\mathrm{mm}$. The highest value of modulus of elasticity based on the type of internal geometry is generated by the sample with an internal geometry of triangle. Meanwhile, based on the size of the axis of symmetry, the highest modulus value is owned by the sample with the internal geometry axis of symmetry $4.5 \mathrm{~mm}$ with a triangle geometry. It is also shown that the modulus of elasticity of the RAW/K sample is $514.363 \mathrm{MPa}$ or lower than the 2 samples with different variations in internal geometry.

Based on these results, it can be seen that differences in internal geometry consisting of thickness (distance) between objects, number of geometries, masses and volumes produce different tensile strength values.

\section{Conclusion}

Internal effect of ABS material geometry that is run using a 3D Printer machine. The difference in internal geometry of triangle and honeycomb printed using a $3 \mathrm{D}$ printer has an effect on the tensile strength of ABS material. The internal geometry with the best mechanical properties is the triangle geometry. Effect of thickness ratio on the height of ABS internal geometry. The ratio of thickness to height (distance) between the internal geometries affects the tensile strength of the objects printed using a 3D printer. The best thickness ratio (distance) between geometries is $2 \mathrm{~mm}$ for objects with triangle and honeycomb geometries.

Authors express appreciation and gratitude for the financial support provided by the Ministry of Education and Culture, Research and Technology, through the 2020 PKUPT funds of Khairun University Ternate.

\section{References}

1. ASTM D 638 : Standard Test Method for Tensile Properties of Plastics. (ASTM International, 2000.

2. ASTM D 790 : Standard Test Methods for Flexural Properties of Unreinforced and Reinforced Plastics and Electrical Insulating Materials (ASTM International, 2000)

3. C.K. Chua, K.F. Leong, C.S. Lim, Rapid Prototyping Principles and Applications (2nd Edition), World Scientific Published Co. Pte. Ltd. Singapore (2003)

4. Enno Ebel, Fabrication of FDM 3D Objects with ABS and PLA and Determination of Their Mechanical Properties, Rtjournal Vol. 1-9 (2014)

5. George E. Dieter, Engineering Design 5th Ed. (New York: McGraw-Hill, 2012)

6. George E. Dieter, Mechanical Metallurgy, McGrawHill International Edition, Materials Science and Engineering Series 3rd Edition, pp.184-206 (1976)

7. I. Hager, A. Golonka, R. Putanowicz, 3D Printing of Buildings and Building Components as the Future of Sustainable Construction, in Procedia Engineering 151, 292 - 299 (2016)

8. M. Bijarimi, S. Ahmad, R. Rasid, Mechanical, Thermal and Morphological Properties of PLA/PP 
Melt Blends, in International Conference on Agriculture, Chemical and Environmental Sciences, 115-117 (2012)

9. O.S. Carneiro, A.F. Silva, R. Gomes, Fused Deposition Modeling with Polypropylene, Materials and Design Journal, 768, 77 (2015)

10. N. Rafiq, Rapid Prototyping Principles and Applications (John Wiley \& Sons Inc., 2006)

11. S. A. Widyanto, Pengembangan Produk Rapid Prototyping Untuk Pembuatan Produk Multi Material, Jurnal Teknik Mesin ROTASI. 2007, 9(4), 10-14 (2016)

12. S. Lubis, Pengaturan Orientasi Posisi Objek pada Proses Rapid Prototyping Menggunakan 3D Printer Terhadap Waktu Proses dan Kwalitas Produk (Universitas Tarumanegara, Jakarta, 2014)

13. T. Galeta, P. Raos, J. Stojsic, I. Paksi, Influence of Structure on Mechanical Properties of 3D Printed Objects, Procedia Engineering 149, 100 - 104 (2016)

14. Z. Amin, Rapid Prototyping Technology: Aplikasi Pada Bidang Medis, in Jurnal Teknik, 3(27), 78-83 (2007)

15. Z.X. Weng, J.L. Wang, T. Senthil. L.X. Wu, Mechanical and Thermal Properties of ABS/Montmorillonite Nanocomposites for Fused Deposition Modeling 3D Printing, Materials and Design 102, $276 \quad-\quad 283$, doi:10.1016/j.matdes.2016.04.045 (2016) 